\title{
Desenvolvendo Habilidades Sociais com Jovens Talentosos: Um Programa e Múltiplas Experiências
}

\author{
Jane Farias Chagas-Ferreira* (D, Daniela Vilarinho-Rezende, \\ Renata Muniz Prado, \& Rayanne Rodrigues de Lima \\ Universidade de Brasília, Brasília, DF, Brasil
}

\begin{abstract}
RESUMO - O objetivo deste artigo é descrever processos e resultados parciais relacionados ao Programa de Desenvolvimento de Habilidades Sociais para Jovens Talentosos. O programa consiste de 13 encontros semanais de 1h40min, centrados em diferentes conjuntos de habilidades como: comunicação, empatia, assertividade, expressão e autocontrole emocional e resolução de conflitos interpessoais. Participaram do programa 128 jovens com idade média de 18,9 anos $(D P=4,93)$. Destacaram-se como aspectos positivos: as atividades de automonitoramento, a mediação dos tutores e as interações no grupo.
\end{abstract}

PALAVRAS-CHAVE: programa, habilidades sociais, talento, superdotação

\section{Social Skills Development Program for Talented Youth: A Program and Multiple Experiences}

\begin{abstract}
The aim of this paper is to describe the processes and partial results related to the Social Skills Development Program for Talented Youth. The program consists of 13 weekly meetings of $1 \mathrm{hr} 40 \mathrm{~min}$ centered on different skills sets of civility, communication, empathy, assertiveness, emotional expression and self-control, and resolution of interpersonal conflicts. One hundred and twenty-eight adolescents with a mean age of 18.9 years old $(S D=4,93)$ participated in the program. The positive aspects were the self-monitoring activities, the tutors' mediation, and the group interactions.
\end{abstract}

KEYWORDS: program, social skills, talent, giftedness

O desenvolvimento socioafetivo e a educação afetiva tem sido pauta de pesquisas, políticas públicas e educacionais. Há uma emergência de abordagens que relacionam aspectos desse desenvolvimento com bem-estar subjetivo, qualidade de vida, sucesso escolar e saúde mental (Cavilla, 2016; França-Freitas, Del Prette, \& Del Prette, 2014). Estudiosos evidenciam a importância de uma formação integral do indivíduo, ressaltam a necessidade do jovem contemporâneo estar preparado para enfrentar problemas de diferentes magnitudes e ponderam que as habilidades necessárias à sua solução dificilmente serão contempladas plenamente em propostas curriculares que enfatizam apenas uma faceta do processo de aprendizagem (Abed, 2014; Santos \& Primi, 2014). Embora o desenvolvimento integral seja preconizado por muitos e inserido em diretrizes educacionais nacionais (Brasil, 2008, 2013, 2014), as estratégias curriculares mais comumente adotadas nas escolas são cognitivistas, prescindindo das dimensões emocionais, sociais e, produtivas ou profissionais.

Ademais, essa constatação se torna relevante especialmente quando se trata do desenvolvimento de jovens com necessidades especiais ou potenciais diferenciados. No caso dos jovens talentosos ou superdotados, há várias pesquisas e estudos demonstrando as peculiaridades no desenvolvimento socioemocional que precisam ser atendidas por meio de estratégias educacionais específicas (Alencar, 2007; Chagas-Ferreira, 2015; Chagas-Ferreira \& Souza,

\footnotetext{
*E-mail: janefcha@gmail.com

- Submetido: 08/09/2016; Revisado: 02/03/2017; Aceito: 11/02/2019.
} 
2018; Chagas \& Fleith, 2010; VanTassel-Baska, Cross \& Olenchak, 2009).

O jovem talentoso possui habilidades gerais ou específicas acima da média, criatividade e envolvimento mais intenso com sua área de interesse. De acordo com Fleith (2007), várias ideias errôneas sobre o desenvolvimento do talento ou superdotação surgem por desconhecimento acerca das características socioemocionais desse grupo. Isso pode suscitar estereótipos ou generalizações equivocadas como associação entre talento e desajuste psicossocial, bem como a ideia de que o indivíduo com potencial intelectual elevado é autossuficiente e não necessita de recursos para seu desenvolvimento.

É fundamental esclarecer que não há um único perfil psicológico para esses indivíduos, apesar de algumas características serem mais frequentes como: perfeccionismo, excesso de autocrítica, sensibilidade exacerbada, perseverança, autoconfiança, senso de humor e de justiça são recorrentes em jovens talentosos. Outro ponto a ser destacado é que não há uma relação direta entre precocidade intelectual e maturidade socioemocional (Chagas-Ferreira, 2014; Ching, 2014; Fergusson, 2011; Ourofino \& Guimarães, 2007). Muitas vezes os pais, ou professores, surpreendem-se com a alta capacidade cognitiva do seu filho, ou aluno, e esperam tal precocidade também no seu comportamento social ou emocional.

Alencar (2007) salienta que essa assincronia entre a idade cronológica, o desenvolvimento intelectual e as necessidades afetivas pode gerar problemas de ordem social. Verifica-se que a possibilidade da ocorrência do desajustamento social não é inerente ao indivíduo talentoso, mas fruto da interação entre suas características pessoais e o ambiente em que está inserido. Pesquisadores da área evidenciam que indivíduos com altas habilidades e com tais características em contextos ambientais apropriados apresentam ajustamento e maturidade socioemocional acima da média, comparados aos seus pares (Fleith, 2007; França-Freitas et al., 2014; Neihart, Reis, Robinson, \& Moon, 2002; Neihart, Pfeiffer \& Cross, 2016; Prado \& Fleith, 2017; Virgolim, 2007). Essa constatação ratifica a necessidade de programas de apoio ou aconselhamento a esses jovens bem como de esclarecimentos aos pais e professores.

Muitas vezes, o jovem com potencial elevado em um domínio, e com alto nível de entusiasmo na realização das tarefas, sente-se incompreendido por não encontrar pares com interesses semelhantes e pela pressão social para se adequarem à norma. Essa condição tende a afetar a autoestima e impactar a performance acadêmica, ocorrendo uma disparidade entre o potencial real e o desempenho revelado. Tal fenômeno é conhecido pelos especialistas como underachievement $\mathrm{e}$ indica que a interação inadequada entre os fatores internos e externos constituem barreiras ao desenvolvimento dos talentos individuais, o que pode levar pessoas talentosas a uma situação de risco social (Cross \& Andersen; 2016; Ourofino \& Fleith, 2011; Tan, Tan, \& Surrendran, 2016).

Os jovens talentosos possuem um modo mais intenso e sensível de responder a estímulos internos ou externos. Essa supersensibilidade, ou alto nível de excitabilidade, foi estudada por Dabrowski, que desenvolveu a Teoria da Desintegração Positiva (Chagas-Ferreira, 2014). Esse autor enfatiza o papel das emoções no processo de desenvolvimento da personalidade, propondo que a mesma evolui de estruturas mais básicas e mais coesas, como o egocentrismo, até níveis superiores, como o altruísmo, compaixão ou empatia. Esse processo se dá por desintegrações e reintegrações, e quanto maior a força dos padrões de excitabilidade maior o potencial de desenvolvimento individual (Oliveira \& Barbosa, 2014). Essa teoria tem sido utilizada para compreender a dimensão e ajustamento socioemocional de indivíduos talentosos.

\section{DESENVOLVIMENTO DE HABILIDADES SOCIAIS}

Nessa perspectiva, em que se busca o desenvolvimento global de crianças e jovens superdotados, vê-se como de fundamental importância discutir o desenvolvimento das habilidades sociais. De acordo com Del Prette e Del Prette (2008), o conceito de habilidades sociais "refere-se à existência de diferentes classes de comportamentos sociais no repertório do indivíduo para lidar de maneira adequada com as demandas das situações interpessoais" (p. 31). Ainda com base nesses autores, existe uma diferença entre os significados dos termos desempenho social, competência social e habilidades sociais. O desempenho social está relacionado à demonstração de um comportamento ou sequências de comportamentos em uma ocorrência social qualquer. Por sua vez, a competência social está associada a situações efetivamente vividas pelo indivíduo, constituindose em um indicador importante por ser bastante preciso para avaliar o ajustamento psicossocial e de perspectivas para o desenvolvimento.

Para Fleury e Murta (2008), durante adolescência acontecem mudanças significativas nas relações sociais, o que demanda repertórios de comportamentos sociais mais elaborados e complexos. Esse jovem está a um passo da inserção no mercado de trabalho, o estabelecimento de relações de intimidade com outras pessoas está se intensificando, a cobrança por pertencer a um grupo é forte e a há necessidade de lidar com todas as dúvidas e inseguranças que se fazem presentes nesse contexto de transição. O desenvolvimento de habilidades sociais pode ser uma estratégia eficiente de enfrentamento das situações mencionadas durante essa fase. Isso ocorre, como apresentam as autoras, devido ao efeito positivo que o desenvolvimento das habilidades sociais tem sobre 
o desenvolvimento socioemocional e a prevenção de psicopatias. Fleury e Murta explicam ainda que a adequação das habilidades sociais ao contexto em que o indivíduo está inserido permite a obtenção de reforçadores valiosos por sua parte. Dessa forma, as relações sociais se tornam extremamente prazerosas e a resolução de problemas do dia a dia mais eficiente.

Dentre as diversas classes e subclasses de habilidades sociais apresentadas na literatura, Del Prette e Del Prette (2008) consideram sete conjuntos de habilidades como mais importantes. São elas: (a) automonitoria: controle da impulsividade, observação do outro, introspecção e reflexão; (b) habilidades sociais de comunicação: fazer e responder perguntas; pedir e dar feedback; gratificar e elogiar; iniciar, manter e encerrar conversação; (c) habilidade social de civilidade: dizer por favor, agradecer, aprasentar-se, cumprimentar, despedir-se; (d) habilidades sociais assertivas, direito e cidadania: manifestar opinião, concordar, discordar; fazer, aceitar e recusar pedidos; desculpar-se e admitir falhas; interagir com autoridade; estabelecer relacionamento afetivo e/ou sexual; encerrar relacionamento; expressar raiva/desagrado e pedir mudança de comportamento; lidar com críticas; (e) habilidades sociais empáticas: parafrasear, refletir sentimentos, expressar apoio; (f) habilidades sociais de trabalho: coordenar grupo; falar em público; resolver problemas, tomar decisões e mediar conflitos; habilidades sociais educativas; e (g) habilidades sociais de expressão de sentimento positivo: fazer amizade, expressar a solidariedade, cultivar o amor.

As habilidades sociais têm sido investigadas em relação a fatores como estilos parentais, desempenho escolar e dificuldades de aprendizagem (e.g. Del Prette \& Del Prette, 2003; Trancoso, 2011), autoeficácia de universitários (e.g., Olaz, Medrano \& Cabanillas, 2011). Os resultados destes estudos demonstraram a eficácia dos programas para o desenvolvimento socioemocional. Estudos realizados com superdotados têm revelado diferenças no desenvolvimento socioemocional desse grupo, principalmente associadas às habilidades sociais de empatia (e.g., Bakar, Ishak \& Abidin, 2014; Ishak, Abidin \& Bakar, 2014). Entretanto, apesar de a literatura de superdotação apresentar alguns aspectos associados às habilidades sociais, pouco se tem discutido e trabalhado acerca do desenvolvimento dessas habilidades em crianças e jovens talentosos. Para entender como os programas de desenvolvimento de habilidades sociais são estruturados, vamos descrever algumas dessas iniciativas a seguir.

\section{PROGRAMAS DE DESENVOLVIMENTO DE HABILIDADES SOCIAIS}

Caballo (2012) relata, que ao longo do tempo foram organizadas técnicas, ferramentas e modelos para explicar e desenvolver as habilidades sociais. Entre os elementos estruturantes de um programa de treinamento em habilidades sociais, o autor aponta: (a) o conjunto de comportamentos específicos que devem ser praticados e integrados ao repertório comportamental; (b) a redução da ansiedade; (c) reestruturação cognitiva por meio das mudanças de valores, crenças e atitudes e (d) a solução de problemas. Para o autor, os programas de treinamento de habilidades sociais utilizam vários procedimentos vinculados à terapia comportamental como: ensaio de comportamento, modelação, reforço, instrução, ensino, tarefas de casa, elaboração de diários, exercícios de resolução de problemas, contratos, discussão em pequenos grupos, leituras selecionadas, filmes etc.

Ainda com base no mesmo autor, os programas de treinamento de habilidades sociais podem ser individuais ou em formato grupal. O programa individual permite a concentração em problemas particulares, podendo-se avaliar progressivamente o desempenho do participante. $\mathrm{O}$ programa em grupo tem várias vantagens como: a interação entre as pessoas, a retroalimentação, a prática entre pares, os ensaios podem ser praticados com outras pessoas do próprio grupo, uso mais eficiente do tempo e os níveis diferenciados de competência social e as experiências dos membros do grupo favorecem a generalização e a transferência de respostas.
O formato dos treinamentos é diverso com maior ou menor quantidade de encontros, abrangendo uma quantidade de classes e subclasses de habilidades diferentes. No entanto, a organização destas estratégias costuma obedecer a seguintes etapas (Caballo, 2012; Del Prette \& Del Prette, 2005): (a) apresentação dos membros do grupo e ambientação; (b) identificação de áreas de maior dificuldade e situações problemas por meio de entrevistas, autorregistros ou emprego de instrumentos como escalas e inventários; (c) análise de comportamentos socialmente habilidosos ou não-habilidosos; (d) reestruturação cognitiva dos modos de pensar por meio de exercícios; (e) ensaios de comportamentos por meio de situações e problemas de vida real; (f) engajamento em atividades ou tarefas de casa; e (g) autoavaliação, avaliação pelo grupo e retroalimentação.

Apesar de serem altamente recomendados na literatura (Ching, 2014; Ferguson, 2011; França-Freitas et al., 2014; Renzulli, 2009), há poucos estudos e programas que possuem enfase no desenvolvimento de habilidades sociais no Brasil. França-Freitas et al. (2014) realizaram pesquisa com 394 crianças com idade entre 8 e 12 anos, sendo que dessas 269 eram identificadas como superdotadas. Os resultados demonstraram que as crianças superdotadas possuíam um repertório de habilidades sociais mais elaborado em todas as classes quando comparadas às demais crianças, com exceção da empatia. Trancoso (2011) realizou estudo com 45 crianças superdotadas com idade entre 7 e 12 anos, que frequentavam 
o ensino fundamental. Os resultados evidenciaram que as crianças mais socialmente habilidosas tinham melhor desempenho acadêmico.

Diante do exposto e dada a escassez de pesquisas, programas ou estratégias educacionais que se destinam ao desenvolvimento de habilidades sociais com jovens superdotados, este estudo de caso tem como objetivo descrever processos e resultados parciais relacionados ao Programa de Desenvolvimento de Habilidades Sociais para Jovens Talentosos. A seguir serão apresentados aspectos estruturantes do Programa, os resultados parciais da primeira oferta e o relato de duas mediadoras.

\section{O PROGRAMA DE DESENVOLVIMENTO DE HABILIDADES SOCIAIS PARA JOVENS TALENTOSOS (PDHSJT):ASPECTOS ESTRUTURANTES}

O Programa de Desenvolvimento de Habilidades Sociais para Jovens Talentosos (PDHSJT) é um projeto de extensão de ação contínua, aberto a toda a comunidade do Distrito Federal e entorno. Tem como seu público-alvo egressos do Atendimento Educacional Especializado ao Aluno Superdotado (AEE-SD), graduandos do curso de psicologia e graduandos que entram em idade precoce na universidade. Seu objetivo é promover o desenvolvimento de habilidades sociais entre jovens com idade entre 16 e 30 anos.

Apesar de ser um projeto de extensão, o Programa foi planejado buscando a integração entre ensino, extensão e pesquisa e o atendimento de demanda levantada entre professores do AEE-SD e alunos egressos desse atendimento que cursavam o ensino superior. Esses alunos e professores indicaram a necessidade de os jovens superdotados se envolverem em atividades educacionais que os auxiliassem no desenvolvimento de habilidades sociais em virtude do reconhecimento de déficits nessa área. Também foram consideras no planejamento do PDHSJT algumas características do desenvolvimento socioemocional desse grupo, amparadas na literatura (Alencar, 2007; ChagasFerreira, 2013, 2014; Chagas-Ferreira \& Souza, 2018;
Ching, 2014; VanTassel-Baska et al., 2009). Entre as quais se destacam: complexidade intelectual e sensibilidade emocional; capacidade ampliada para responder a vários estímulos externos e internos simultaneamente; motivação, concentração e produção em suas áreas de conhecimento por um tempo mais prolongado; busca pela perfeição; consciência mais aguçada de si mesmos, senso de justiça e desenvolvimento moral mais avançado; e senso de humor incomum.

Ainda identificamos algumas características que podem dificultar a socialização desses jovens com seus pares como: independência intelectual, altos níveis de motivação intrínseca, concentração e envolvimento com atividades de seu interesse, complexidade de raciocínio, intensidade e oscilação emocional, introversão, perfeccionismo e necessidade de autoconhecimento e autoaceitação (Chagas \& Fleith, 2010; Chagas-Ferreira, 2013; Chagas-Ferreira \& Souza, 2018). Entre os problemas socioemocionais mais recorrentes são apontados a tendência ao isolamento social, a negação do talento, e o perfeccionismo neurótico que desencadeia altos níveis de frustração e ansiedade (Fleith, 2007).

\section{COMPOSIÇÃO DA EQUIPE}

A equipe que atuava no Programa era composta por professor-supervisor, monitores, mediadores e bolsistas de extensão. Cada um desses atores tinha papel específico na implementação do Programa e na condução dos encontros. A coordenadora do Programa atuava como professorasupervisora. As atividades de supervisão eram realizadas por meio de encontros semanais de estudo, orientação e avaliação das estratégias e dinâmicas adotadas nos encontros grupais. $\mathrm{O}$ alinhamento das atividades previstas, visando atender as especificidades de cada grupo, era discutido e planejado com toda a equipe.

Os monitores e mediadores eram graduandos, estagiários ou pós-graduandos do curso de psicologia que concluíram o Programa. Inicialmente, foram indicados pelo professor-supervisor para auxiliarem como monitores. Esses monitores tornam-se mediadores a partir do momento em que assumem a gestão de um grupo e a formação de outros monitores e bolsistas de extensão. Os bolsistas de extensão além de atuarem como monitores também auxiliavam nos processos operacionais do funcionamento do Programa, como: elaboração e controle de listas de frequência, divulgação de datas e eventos, impressão de cópias para os encontros, manutenção de banco de dados do programa etc. Essa dinâmica visava não somente a manutenção do fluxo de formação de novos monitores e mediadores, mas o aprofundamento e apropriação dos conhecimentos, o fomento de pesquisas e a prática profissional. 


\section{MATERIAIS DE APOIO E INSTRUMENTOS}

Para viabilizar a implementação do PDHSJT foram elaborados materiais de apoio para cada encontro, com conteúdo específico para os participantes e mediadores/ monitores. Além desses materiais são utilizados o Inventário de Habilidades Sociais - IHS (Del Prette \& Del Prette, 2001) e questionários avaliativos.

\section{Materiais de Apoio}

São encartes contendo conteúdo para leitura, descrição de atividades de automonitoramento semanais, ensaios comportamentais, exercícios, dinâmicas, vivências e outros recursos associados ao conjunto de habilidades sociais que será trabalhado em cada encontro. $\mathrm{O}$ encarte dos mediadores e monitores contém um script sequenciado e detalhado dos processos, dinâmicas e técnicas a serem utilizados.

\section{Inventário de Habilidades Sociais (IHS - Del Prette)}

É um instrumento de autorrelato que avalia as dimensões situacionais e comportamentais. O inventário é composto por 38 itens com uma escala que vai de nunca ou raramente a quase sempre e sempre, relacionados a cinco fatores: Enfrentamento e Autoafirmação com Risco, Autoafirmação na Expressão de Sentimento Positivo, Conversação e Desenvoltura Social, Autoexposição a Desconhecidos e Situações Novas, e Autocontrole da Agressividade. O instrumento é validado (Del Prette \& Del Prette, 2001).

\section{Questionários}

Os estudantes preenchiam no ato de inscrição ou no primeiro encontro um questionário com perguntas sobre aspectos sociodemográficos, expectativas em relação à participação no programa e percepção sobre a competência social. Outro questionário era aplicado no último encontro. Esse segundo questionário era composto por perguntas fechadas e abertas que avaliam vários aspectos estruturais do Programa como: conteúdo dos encartes, mediação dos membros da equipe, atendimento de expectativas e nível de satisfação e a interação com os demais participantes do grupo.

\section{ORGANIZAÇÃO DOS ENCONTROS}

O Programa de Desenvolvimento de Habilidades Sociais para Jovens Talentosos está estruturado em 13 encontros com duração média de 1 h40min. Em cada um desses encontros é trabalhado um conjunto de habilidades sociais, selecionado com base na literatura sobre o desenvolvimento socioemocional de indivíduos superdotados e talentosos. As habilidades trabalhadas são: civilidade, comunicação verbal e não-verbal, expressividade e autocontrole emocional, empatia e amizade, assertividade e cidadania, resolução de conflitos interpessoais.

Cada encontro possui estrutura geral semelhante, com exceção do primeiro, segundo e último encontros. No primeiro encontro, são estabelecidos os acordos de funcionamento do grupo, são apresentados os objetivos e a dinâmica do Programa e preenchido o questionário inicial. No segundo e último encontros é aplicado o Inventário de Habilidades Sociais. Ainda no último encontro é realizada dinâmica de troca de experiências e avaliação do Programa por meio de questionário. Nos demais encontros o delineamento tem o seguinte contorno: (a) acolhimento e técnicas de relaxamento, (b) relato sobre a atividade prática da semana anterior, (c) desenvolvimento do conteúdo do encontro por meio de dinâmicas, vivências, ensaios comportamentais e leitura de texto específico, (d) descrição da próxima atividade de automonitoramento semanal, (e) avaliação do encontro, e (f) despedida.

Os encontros foram realizados em sala de atendimento coletivo de um centro de atendimento e estudos psicológicos e em salas do AEE-SD. Para a efetivação da parceria com AEE-SD, fica sob a responsabilidade da coordenação regional (1) destinar a sala do AEE-SD onde o Programa será implementado, (2) fazer as inscrições prévias dos alunos que participarão do Programa e (3) providenciar e assegurar ambiente físico adequado ao desenvolvimento das atividades previstas para cada encontro. Os recursos humanos, instrumentos e materiais de apoio são providos pelo Programa.

\section{RESULTADOS PARCIAIS RELACIONADOS À PRIMEIRA OFERTA DO PDHSJT}

O PDHSJT foi iniciado no primeiro semestre de 2013, quando foram elaborados os encartes do monitor e do participantes. Os resultados parciais apresentados nesse estudo abrangem a primeira oferta do Programa (20132015). A turma piloto foi formada por sete alunos, sendo três alunos do curso de psicologia e quatro alunos oriundos 
de outros cursos da UnB, dois deles com diagnóstico de superdotação.

Nesse período foram ofertadas onze turmas, com um total de 128 participantes com idade média de 18,9 anos $(\mathrm{DP}=4,93)$, destes $32,7 \%$ do gênero masculino e $67,3 \%$ do gênero feminino. Entre os participantes, 44 eram alunos ou egressos do AEE-SD, 59 eram graduandos em psicologia, 21 eram graduandos de outros cursos e 4 não informaram. A maioria dos jovens talentosos cursava o Ensino Médio, apenas 5,3\% cursavam o Ensino Fundamental - Séries
Finais. Participaram como monitores e mediadores duas doutorandas e seis graduandos do curso de psicologia. Com relação ao funcionamento das turmas, quatro turmas funcionaram em três salas do AEE-SD e sete em um Centro de Atendimento e Estudos Psicológicos.

Os resultados da aplicação do Inventário de Habilidades Sociais indicaram que houve uma melhora significativa nos cinco fatores avaliados e no escore geral conforme pode ser observado na Tabela 1.

Tabela 1

Resultados do Pré e Pós-Teste do Inventário de Habilidades Sociais $(n=34)$

\begin{tabular}{|c|c|c|c|c|c|}
\hline Fatores & $\begin{array}{l}\text { Pré-teste } \\
M(D P)\end{array}$ & $\begin{array}{l}\text { Pós-teste } \\
M(D P)\end{array}$ & $t$ & $d f$ & $p$ \\
\hline Escore Geral & $45.7(29.3)$ & $66.5(30.4)$ & -4.9 & 26 & $<0.01$ \\
\hline Fator 1: Enfrentamento e Autoafirmação com risco & $46.5(28.5)$ & $61.7(29.1)$ & -4.0 & 26 & $<0.01$ \\
\hline Fator 2: Autoafirmação na expressão de sentimento positivo & $47.4(25.0)$ & $64.8(26.7)$ & -4.6 & 26 & $<0.01$ \\
\hline Fator 3: conversação e desenvoltura social & $46.0(34.1)$ & $71.1(32.8)$ & -4.1 & 26 & $<0.01$ \\
\hline Fator 4: autoexposição a desconhecidos e situações novas & $58.1(26.3)$ & $67.4(26.5)$ & -2.1 & 26 & 0.047 \\
\hline Fator 5: autoexposição a desconhecidos e situações novas & $41.1(21.3)$ & $56.7(25.5)$ & -4.2 & 26 & $<0.01$ \\
\hline
\end{tabular}

Ao final de cada turma do Programa, os participantes preencheram um questionário avaliativo contendo itens sobre aspectos estruturais, interacionais, de atendimento das expectativas e satisfação. Entre os participantes que responderam ao questionário final $(\mathrm{n}=34), 98,3 \%$ avaliou o programa como muito ou altamente satisfatório em relação ao atendimento de suas expectativas, a dinâmica dos encontros, a mediação dos monitores, a qualidade e relevância do material impresso, a pertinência das atividades de automonitoramento semanais como facilitadoras do desenvolvimento das habilidades sociais, e com relação à interação do grupo em termos de receptividade, respeito, relações harmoniosas e amigáveis.

Entre os aspectos positivos mencionados, destacaramse o acolhimento, a dinâmica e relacionamento interativo entre os membros do grupo nos encontros, a amizade, a promoção do autoconhecimento, as discussões das atividades de automonitoramento, a reflexão sobre os próprios comportamentos, a melhoria nos processos comunicativos e de como lidar com as pessoas e a própria evolução social. Elencamos alguns exemplos de relatos da avaliação positiva dos participantes: "O melhor foi o aprendizado de maneira dinâmica, sem tanta cobrança, porém com compromisso."; "Eu aprendi a ser assertivo e melhorei minhas amizades."; "Os temas abordados de muita reflexão, me ajudou a entender muitos sentimentos, melhorar meus hábitos; me surpreendi muito comigo mesma"; "Esse programa me ajudou no autoconhecimento e no aprendizado, e agora sou um ser socialmente mais consciente dos meus atos."; "Excelente programa, qualidade nos materiais, assiduidade da professora e boa interação com o grupo".

Entre os aspectos negativos foram destacados a duração do programa considerada insuficiente $(n=5)$, pois os participantes gostariam de continuar por mais tempo desfrutando da companhia do grupo e envolvidos em outras atividades; e outros lamentaram o fato de ter perdido algum encontro $(n=4)$, por conta da distância onde o atendimento era realizado, gerenciamento do tempo e por motivos pessoais. Como exemplo desse tipo de relato, destaca-se: "Durou pouco"; "Pela disponibilidade do horário acabei perdendo algumas aulas."; "Foi a distância do curso para minha casa"; "Por causa da programação de tempo, acabei perdendo algumas lições". 


\section{RELATO DE EXPERIÊNCIA ACERCA DE UM GRUPO ATENDIDO NO CENTRO DE ATENDIMENTO E ESTUDOS PSICOLÓGICOS}

Participaram da turma, 16 universitários, 52,2\% eram alunos do curso de Psicologia, 18,6\% eram graduandos de outros cursos e $2,7 \%$ não informaram. Seis alunos eram do sexo masculino e 8 do gênero feminino. A faixa etária média do grupo era de 21,5 anos $(D P=5,39)$.

A estrutura dos encontros obedeceu ao que foi proposto para cada encontro, conforme descrito anteriormente. $\mathrm{O}$ primeiro encontro foi importante para o estabelecimento de vínculo entre o grupo, de regras sobre horários, da participação e do compromisso com a confidencialidade. No segundo encontro foi aplicado o Inventário de Habilidades Sociais (IHS- Del Prette), e alguns conceitos sobre tais habilidades foram esclarecidos. No terceiro encontro observou-se um aprofundamento dos relatos dos participantes, que expressaram seus sentimentos e angústias. Verificou-se que se encontravam em um espaço seguro para compartilhar aspectos das suas experiências socioemocionais, positivas e negativas. Os resultados da avaliação do IHS foram entregues e discutidos com os participantes. O quarto encontro ocorreu conforme planejado sem maiores observações. Já o encontro cinco teve como objetivo desenvolver habilidades de comunicação e o desafio expresso pelo grupo foi o de desenvolver a habilidade de escuta.

O encontro seis tratou do tema das emoções, formas de expressão e identificação em si e nos outros. Nos encontros seguintes percebeu-se um nítido desenvolvimento do grupo, não só no nível dos relatos, mas na interação entre os membros. O oitavo e nono encontros tiveram como objetivo o desenvolvimento da assertividade e empatia, os participantes manifestaram ter grande necessidade de treinarem essas habilidades, e se mostraram muito motivados nesses encontros. Nos encontros 10, 11 e 12, buscou-se promover a habilidade social de fazer amigos e de resolução de conflitos. No encontro final realizou-se a avaliação do Programa e um piquenique para o encerramento das atividades do grupo com a celebração das conquistas pessoais.

A participação como monitora surgiu do interesse em desenvolver competências para liderar e conduzir atividades em grupo. $\mathrm{O}$ cunho psicoeducativo deste tipo de intervenção foi bastante favorável ao desenvolvimento de várias habilidades sociais educativas do mediador. A experiência adquirida no planejamento, preparação dos scripts e condução dos encontros permitiu uma vivência prática em um contexto acadêmico que é predominantemente teórico. A participação no Programa promove um alto nível de engajamento com seus objetivos, o que leva a maioria dos monitores a se manterem vinculados em alguma medida com suas finalidades, seja no planejamento de outras iniciativas com o mesmo foco, na iniciação científica, ou na elaboração de projetos de pesquisa. Como uma das mediadoras de vários grupos, e quarta autora deste trabalho, fui despertada para a pesquisa, com isso, iniciei mestrado com foco em habilidades sociais, superdotação e avaliação de programas.

\section{RELATO DE EXPERIÊNCIA ACERCA DE GRUPO ATENDIDO NA SALA DE ATENDIMENTO ESPECIALIZADO AO ALUNO SUPERDOTADO}

No segundo semestre do ano de 2013, foi implementado o PDHSJT em uma sala do AEE-SD de uma escola pública. Duas mediadoras coordenaram o grupo e foram realizados 12 encontros, necessitando que a $12^{\mathrm{a}}$ e a $13^{\mathrm{a}}$ unidades fossem efetivadas em um só dia por conta das férias escolares.

Ao longo do Programa houve evasão dos participantes, permanecendo frequentes apenas cinco dos nove inscritos. A desistência deveu-se, principalmente, ao fato de os participantes terem que assistir aulas regulares na parte da manhã, voltar às suas casas para almoçar e, em seguida, retornarem para participar dos encontros à tarde. Aqueles que permaneceram até o final fortificaram os vínculos entre si, demonstraram alto grau de comprometimento com os objetivos do Programa e relataram ter se beneficiado com as atividades propostas.

Dentre as vivências avaliadas como mais relevantes, foi citada uma atividade relacionada a fazer e receber elogios. Como aqueles jovens estavam habituados a conviver com críticas, aqueles elogios mobilizaram de forma positiva a relação do grupo, contribuindo para o fortalecimento dos vínculos e para a melhoria da autoestima e autoconceito.
No encontro final, os jovens expressaram grande alegria e relataram a importância de terem participado do Programa. Um dos adolescentes que não pode continuar no grupo fez questão de participar desse último momento e entregou às mediadoras uma carta explicando as razões de sua desistência e avaliando de forma muito positiva os encontros em que pode estar presente, expondo como as dinâmicas e vivências contribuíram para a resolução de conflitos interpessoais.

A experiência na mediação desse grupo foi extremamente satisfatória e gratificante. Além do crescimento como profissional, que advém de lidar com os desafios e surpresas que a realidade nos apresenta, os laços criados entre os participantes e as mediadoras ao longo do dos encontros possibilitaram diversas reflexões sobre as relações interpessoais e o desenvolvimento humano. Os feedbacks dos participantes indicaram que, em alguma medida, o Programa fez diferença em suas vidas e nas das pessoas que conviviam com eles. A possibilidade de ver o florescimento de jovens tão talentosos enriqueceu nossas vivências e práticas. 


\section{CONSIDERAÇÕES FINAIS}

Os resultados parciais demonstram a efetividade do Programa quanto ao desenvolvimento das habilidades sociais trabalhadas por meio da avaliação qualitativa de participantes e mediadores e da análise dos escores do pré e pós-teste do Inventário de Habilidades Sociais. Ainda fica evidenciada a sua articulação com o ensino, extensão e pesquisa e relevam a necessidade de refinamento de estratégias de acesso dos egressos e participantes do AEESD, uma vez que correspondem a aproximadamente $1 / 4$ dos participantes atendidos até o momento.

O Programa iniciou sua segunda oferta: a primeira fase do Programa está em processo de avaliação visando a melhoria e refinamento da proposta e os materiais de cada encontro foram revisados e encontram-se em fase de editoração para publicação. Dois novos desafios estão sendo explorados numa perspectiva de pesquisa-intervenção: a formação de professores e o desenvolvimento de habilidades sociais entre crianças em situação de risco e vulnerabilidade social. Ambas as iniciativas tiveram um primeiro piloto já realizado. Além das pesquisas em andamento, dos atendimentos em curso, das apresentações em congressos, a equipe tem trabalhado na adequação do material para crianças menores e na formação de novos monitores para a ampliação do Programa que tem uma demanda crescente a cada semestre. A experiência continua.

\section{REFERÊNCIAS}

Abed, A. L. Z. (2014). O desenvolvimento das habilidades socioemocionais como caminho para a aprendizagem e o sucesso escolar de alunos da educação básica. Construção psicopedagógica. Retirado de http://pepsic.bvsalud.org/scielo. php?script=sci_arttext \&pid =S1415-69542016000100002

Alencar, E. M. L. S. (2007). Características socioemocionais do superdotado: Questões atuais. Psicologia em Estudo (Maringá), 12, 371-378.

Almeida, L. S., Fleith, D. S., \& Oliveira, E. P. (2013). Sobredotação: Respostas educativas. Braga, Portugal: ADIPSIEDUC.

Bakar, A. Y. A., Ishak, N. M., \& Abidin, M. H. Z. (2014). The relationship between domains of empathy and leadership skills among gifted and talented students. Procedia - Social and Behavioral Sciences, 116, 765-768.

Brasil. (2008). Política nacional de educação especial na perspectiva da educação inclusiva. Brasília: MEC, SEESP.

Brasil. (2013). Diretrizes curriculares nacionais gerais para a Educação Básica: diversidade e inclusão. Brasília: CNE, MEC, SECADI.

Brasil. (2014). Plano nacional de educação. Lei 13.005/2014. Brasília: Presidência da República.

Caballo, V. E. (2012). Manual de avaliação e treinamento das habilidades sociais. São Paulo: Santos.

Cavilla, D, (2016). Taxonomy of affective curriculum for gifteds learners (Doctoral dissertation). Retirado de http://stars.library. ucf.edu/cgi/viewcontent.cgi?article 5943\&context=etd

Chagas, J. F. (2007). Conceituação e fatores individuais, familiares e culturais relacionados às altas habilidades. In D. S. Fleith \& E. M. L. S. Alencar (Eds.), Desenvolvimento de talentos e altas habilidades: Orientação a pais e professores (pp. 15-23). Porto Alegre: Artmed.

Chagas, J. F., \& Fleith, D. S. (2010). Habilidades, características pessoais, interesses e estilos de aprendizagem de adolescentes talentosos. PsicoUSF, 15, 93-102.

Chagas-Ferreira, J. F. (2013). Hannah, uma trajetória de superação. In D. S. Fleith \& E. M. L. S. Alencar (Eds.), Superdotados: Trajetórias de desenvolvimento e realizações (pp. 41-54). Curitiba: Juruá.

Chagas-Ferreira, J. F. (2014). Características socioemocionais do indivíduo talentoso e a importância do desenvolvimento de habilidades sociais. In A. M. R. Virgolim \& E. Konkiewitz (Eds.), Altas habilidades/superdotação, inteligência e criatividade: Uma visão multidisciplinar (pp. 98-111). Campinas: Papirus.
Chagas-Ferreira, J. F. (2016). O desenvolvimento do talento numa perspectiva do curso de vida. In M C. S. L. Oliveira, J. F. Chagas-Ferreira, G. M. M. Mieto, \& R. Beraldo (Eds.), Psicologia dos processos de desenvolvimento humano: Educação e cultura (pp. 117-136). Curitiba: Átomo e Alínea.

Chagas-Ferreira, J. F., \& Souza, R. A. R. (2018). O desenvolvimento socioemocional de superdotados: Descrevendo singularidades e identificando possibilidades de atendimento. In F. H. R. Piske, T. Stoltz, C. Costa-Lobo, A. Rocha, \& E. Vásquez-Justo (Orgs.), Educação de superdotados e talentosos: Emoção e criatividade (pp. 127-138). Curitiba: Juruá.

Ching, B. (2014). Affective curriculum for gifted students in Malaysia: A recommendation. Journal for the education of the Young scientist and giftedness, 2, 11-21.

Cross, T. L., \& Andersen, L. (2016). Depression and suicide among gifted children and adolescents. In M. Neihart, S. L. Pfeiffer, \& T. L. Cross (Eds.), The social and emotional development of gifted children: What do we know? (2 $2^{\mathrm{a}}$ ed., pp. 79-90). Washington: Prufrock Press.

Del Prette, Z. A. P., \& Del Prette, A. (2001). Inventário de Habilidades Sociais (IHS-Del-Prette): Manual de aplicação, apuração e interpretação. São Paulo, SP: Casa do Psicólogo.

Del Prette, Z. A. P., \& Del Prette, A. (2003). Habilidades sociais e dificuldades de aprendizagem: Teoria e pesquisa sob um enfoque multimodal. In A. Del Prette \& Z. A. P. Del Prette (Eds.), Habilidades sociais, desenvolvimento e aprendizagem: Questões conceituais, avaliação e intervenção (pp. 167-206). Campinas, SP: Alínea.

Del Prette, Z. A. P., \& Del Prette, A. (2005). Psicologia das habilidades sociais na infância: Teórica e prática. Petrópolis, RJ: Vozes.

Del Prette, A., \& Del Prette, Z. A. P. (2008). Psicologia das relações interpessoais: Vivencias para o trabalho em grupo. Petrópolis, RJ: Vozes.

Fergusson, S. (2011). A case for affective educatioin: adressing the social and emotional needs of gifetd students. Retirado de $\mathrm{http}$ //sengifted.org/a-case-for-affective-education-addressingthe-social-and-emotional-needs-of-gifted-students-in-theclassroom/

Fleith, D. S. (2007). Altas habilidades e desenvolvimento sócioemocional. In D. S. Fleith \& E. M. L. S. Alencar (Eds.), Desenvolvimento de talentos e altas habilidades: Orientação a pais e professores (pp. 41-50). Porto Alegre: Artmed. 
Fleury, A. L., \& Murta, S. G. (2008). Contribuições do treinamento em habilidades sociais para o desenvolvimento de adolescentes trabalhadores. In S. G. Murta (Ed.), Grupos psicoeducativos: Aplicações em múltiplos contextos (pp. 83-90). Goiânia, GO: Porã Cultural.

França-Freitas, M. L. P., Del Prette, A., \& Del Prette, Z. A. P. (2014). Habilidades sociais de crianças dotadas e talentosas. Estudos de Psicologia (Natal), 19(4), 288-295. ISSN 1413-294X. http:// dx.doi.org/10.1590/S1413-294X2014000400006.

Ishak, N. M., Abidin, M. H. Z., \& Bakar, A. Y. A. (2014). Dimensions of social skills and their relationship with empathy among gifted and talented students in Malaysia. Procedia Social and Behavioral Sciences, 116, 750-753.

Neihart, M., Reis, S. M., Robinson, N. M., \& Moon, S. M. (Eds.) (2002). The social and emotional development of gifted children: What do we know? Washington: Prufrock Press.

Neihart, M., Pfeiffer, S. L., \& Cross, T. L. (Eds.). (2016). The social and emotional development of gifted children: What do we know? (2. ed.). Washington: Prufrock Press.

Olaz, F. O., Medrano, L. A., \& Cabanillas, G. A. (2011). Programa vivencial versus programa instrucional de habilidades sociais: Impacto sobre autoeficácia de universitários. In A. Del Prette \& Z. A. P. Del Prette (Eds.), Habilidades sociais: Intervenções efetivas em grupo (pp. 175-201). São Paulo, SP: Casa do Psicólogo.

Oliveira, J. C., \& Barbosa, A. J. G. (2014). Instrumentos de sobreexcitabilidade: Uma revisão sistemática. Arquivos Brasileiros de Psicologia, 66(1), 117-134.

Ourofino, V. T. A. T., \& Fleith, D. S. (2011). A condição underachievement em superdotação: Definição e características. Psicologia Teoria e Prática, 13, 206-222

Ourofino, V. T. A. T., \& Guimarães, T. G. (2007). Características intelectuais, emocionais e sociais do aluno com altas habilidades/superdotação. In D. S. Fleith (Ed.), A construção de práticas educacionais para alunos com altas habilidades/ superdotação. Orientação a professores (pp. 4152). Brasília: MEC, SEESP.

Prado, R. M., \& Fleith, D. S. (2017). O papel do aconselhamento psicológico no desenvolvimento afetivo do aluno superdotado. In F. H. R. Piske, C. L. B. Vestena, T. Stoltz, J. M. M. Barby, S. Bahia, \& S. P. Freitas (Orgs.), Processos afetivos e cognitivos de superdotados e talntosos (pp. 209-224). Curitiba: Editora Prisma.

Renzulli, J. (2009). Operation houndstooth: A positive perspective on developing social inteligence. In J. L VanTassel-Baska, T. L., Cross, T. L., \& F. R. Olenchak, F. R. (Eds.), Social-emotional curriculum with gifted and talented students (pp. 79-113). Waco, TX: Prufrock Press.

Tan, L. S., Tan, K. C. K., \& Surrendran, D. (2016). Gifted underachievement. In M. Neihart, S. L. Pfeiffer \& T. L. Cross (Eds.), The social and emotional development of gifted children: What do we know? (2 ${ }^{\mathrm{a}}$ ed., pp. 91-102). Washington: Prufrock Press.

Trancoso, B. S. (2011). Percepções de alunos superdotados acerca das relações entre desenvolvimento socioemocional e desempenho acadêmico (Dissertação de mestrado). Universidade Federal do Paraná. Retirado de http://oasisbr. ibict.br/vufind/Record/ UFPR 79a95b0583e0ef11cdb6941f4 2e786a3/Details

VanTassel-Baska, J. L., Cross, T. L., \& Olenchak, F. R. (Eds.). (2009). Social-emotional curriculum with gifted and talented students. Waco, TX: Prufrock Press.

Virgolim, A. M. R. (2007). Como reconhecer a criança superdotada? As características cognitivas, afetivas e sociais do superdotado. In A. M. R. Virgolim (Ed.), Altas habilidades/superdotação: Encorajando potenciais (pp. 41-49). Brasília: MEC, SEESP. 